\title{
REVIEW OF THE ANALYTICAL ASSESSMENT METHOD OF FINDING THE SEISMIC AND EXTREME LOAD RESILIENCE OF SHEAR LINKS
}

\author{
Lidiia Kondratieva*, Aleksandr Kuznetsov, Ekaterina Moiseyeva \\ Saint Petersburg State University of Architecture and Civil Engineering \\ Vtoraja Krasnoarmeyskaya st., 4, Saint Petersburg, Russia
}

${ }^{*}$ Corresponding author: kondratjevaln@yandex.ru

\begin{abstract}
Introduction: This paper reviews the analytical method of assessing the seismic and extreme load resistance of buildings with a complex macrostructure that includes elastic-plastic inserts operating in shear. Methods: We analyze a number of studies that rationalize the choice of models for simulating complex elastic-plastic deformation in a mechanical system with several degrees of freedom, as well as studies that review the durability and resilience of buildings with a complex macrostructure based on non-linear shear links when subjected to dynamic and extreme impact. We also consider the methods of structural analysis regarding buildings with elastic-plastic inserts, accounting for the plastic hinged joints of metal frames. Results: We apply the analytical method to linear and non-linear systems with $n$ degrees of freedom. We propose a mathematical equation that describes the nature of shear link response to seismic and extreme loads. Our method makes it possible to obtain an analytical solution for structures with proportionate and disproportionate damping by using the direct integration algorithm. Discussion: Most structures with a broad range of construction material properties require a disproportionate damping model. In this study, we solve equations by using the direct integration algorithm based on disproportionate damping. Under high dynamic load, the reinforcement of shear inserts operates in a plastic state.
\end{abstract}

Keywords

Analytical assessment method, seismic load, extreme impact, elastic-plastic insert.

\section{Introduction}

Structural integrity can be preserved through the use of elastic-plastic inserts (EPIs), which exhibit elastic-plastic properties and ensure that the expansion joints remain flexible enough to withstand dynamic and extreme impact. EPIs reduce the risk of destruction and buckling in buildings and structures that are subjected to seismic activity and extreme conditions. By adjusting the EPI stiffness characteristics, one can control the dynamic parameters of buildings and structures. There have been some studies on the stiffness characteristics of such inserts in buildings with a complex macrostructure, but an examination of Russian and foreign published research has not revealed any instances of reviewing the analytical methods of assessing how EPIs impact the stress-strain state of buildings with a complex macrostructure when subjected to seismic and extreme load. Therefore, it would be highly relevant to study the methods of assessing the stress-strain state of buildings having a complex macrostructure with elastic-plastic inserts in dynamic or extreme conditions.

In (Rutman, 2013), Professor Yu. L. Rutman looks at the ways in which hardening is accounted for within elastic-plastic macro models; whereas in (Rutman, 2012), he studies a model of complex elastic-plastic deformation, applicable to mechanical systems with several degrees of freedom. Rutman's students also propose solutions for determining the parameters of a force diagram for structural elements subject to plastic deformation (Rutman et al., 2007). They deploy a macro model method for assessing the maximum earthquake magnitude that frame structures can withstand (Nidzhad, 2014) and analyze the results of dynamic elastic-plastic analysis based on models with both one and several degrees of freedom (Simbort, 2011).

In turn, Professor V. I. Pletnev and his circle were interested in the issues of dynamic and extreme impact on the durability and resilience of buildings with a complex macro structure based on non-linear shear links (Golykh et al., 2010, 2011; Samsonov, 2003; Smirnov, 2008). Direct integration-based solutions of equations describing structures with disproportionate damping are provided in (Samsonov, 2003). The experiment description and result analysis may be found in (Omori, 1900; Pletnhov and Nguyen, 2011).

Another study (Nguyen and Kondratieva, 2013) demonstrates, through analytical and numerical methods, how elastic-plastic inserts impact the free vibration of a polyhedral shell. A study by SanchezRicart and Plumier (2008) contains a force analysis, accounting for the plastic hinged joints of metal frames. 
Finally, several more studies (Bataev et al. 2016; Chepurnenko et al., 2016, 2019) examine an analytical method of assessing stresses in reinforced-concrete slabs and wall panels with account for creep.

\section{Methods}

The main focus of all researchers is structural resilience. High-rise buildings are sensitive to seismic activity, which causes major displacements and creates substantial stress within the loadbearing structures. This issue can be resolved through installing damping tools: special elasticplastic inserts (Fig. 1) that will allow the building to remain usable even in extreme conditions. As the segments of the building shift significantly in relation to each other, the building will continue to function and retain its general resilience through the redistribution of forces.

There are many known versions of damping tools, which require analysis and clear recommendations for usage under specific conditions. In this paper, we take a look at the EPIs represented in a diagram in Figure 2. The size and shape of elastic-plastic inserts depend on the extent and direction of the current load, as well as on the geometrical parameters and stiffness characteristics of buildings and structures. Such inserts are going to act as dampers in dynamic and extreme conditions.

Under high dynamic load, the reinforcement of shear inserts operates in a plastic state.

When describing the shear insert operation, it is important to find a mathematical equation that would properly characterize the studied object. We propose the following analytical solution for bearing seismic load:

$$
M \ddot{u}+C \dot{u}+K u=-M E_{x} \ddot{X}_{0}(t),
$$

where $\ddot{u}$ is the acceleration vector, $\dot{u}$ is the speed vector, $u$ is the localized mass displacement vector; $M$ is the mass matrix; $C$ is the dissipation matrix; $K$ is the stiffness matrix; $E x$ is the modulus of elasticity; $\ddot{X}_{0}(t)$ is the soil acceleration.

We can solve equation (1) within the threedimensional coordinate system, accounting for the three components of seismic acceleration

$$
\ddot{X}_{0}(t) ; \ddot{Y}_{0}(t) 8 \ddot{Z}_{0}(t) \text { : }
$$

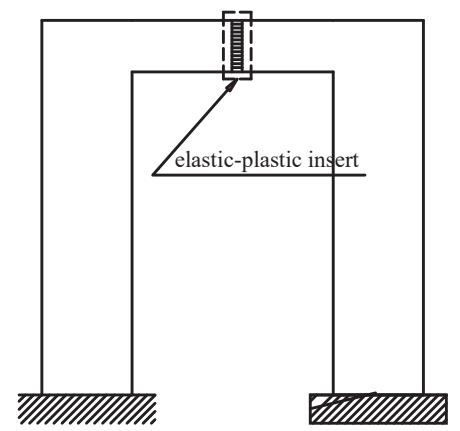

Figure 1. Diagram of a high-rise building with an EPI

$$
\begin{gathered}
M \ddot{u}+C \dot{u}+K u=-M\left(E_{x} \ddot{X}_{0}(t)+\right. \\
\left.+E_{y} \ddot{Y}_{0}(t)+E_{z} \ddot{Z}_{0}(t)\right),
\end{gathered}
$$

where $E_{x}(t) ; E_{y}(t) a n d E_{z}(t)$ components are also defined within the three-dimensional coordinate system.

If the system is linear, we can apply the eigenfunction expansion method. It can be briefly described as follows:

1. Create the initial matrices: dissipation matrix $C$, stiffness matrix $K$, and mass matrix $M ; 2$. Find the eigenfrequencies and eigenmodes of the system.

Note that we do not account for damping when determining the eigenfrequencies and eigenmodes. The frequencies and modes are viewed as eigenvalues:

$$
\begin{aligned}
& \left(K-\omega^{2} M\right) \cdot \theta=0 ; \\
& \operatorname{det}\left(K-\omega^{2} M\right)=0 .
\end{aligned}
$$

Eigenvector with the mass matrix:

$$
\varphi_{k}^{T} M \varphi_{k}=1 .
$$

3. Find the normal components of the system.

In a forced vibration description, the displacement amplitude vector is determined through coordinate transformation:

$$
u=\Phi q ; u=\Phi q ;
$$

where $\Phi$ is the transformation matrix:

$$
\Phi^{T}=\left(\phi_{1}, \phi_{2}, \ldots \phi_{n}\right) .
$$

We shall now substitute (3) in (2) and, accounting for (4), arrive at the following conclusion:
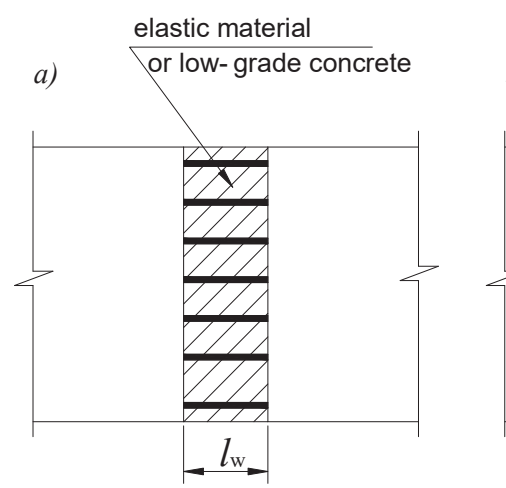

elastic material or low- grade concrete

b)

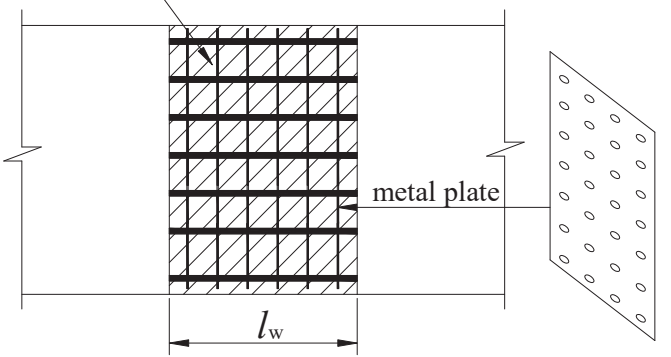

Figure 2. Diagrams of elastic-plastic inserts: a) for small $L_{B}$ values; b) for large $L_{B}$ values, with longitudinal reinforcement and transverse metal plates and rubber buffers 


$$
\Phi^{T} M \Phi \ddot{q}+\Phi^{T} C \Phi \dot{q}+\Phi^{T} K \Phi q=-\Phi^{T} M E_{x} \ddot{X}_{0}(t) .
$$

Let us now apply the orthogonality condition:

$$
\Phi^{T} M \Phi=I
$$

After several mathematical operations, we find:

$$
\Phi^{T} K \Phi=\omega .
$$

It is possible to meet the following conditions:

$$
\phi_{i}^{T} C \phi_{j}=0(i \neq j) ; \quad \phi_{i}^{T} C \phi_{j}=2 \beta_{i} \omega_{i}(i=j) .
$$

When conditions (8) are met, the system of equations (1) is going to branch into $n$ independent equations. Each of them will be defined by generalized coordinate $q_{i}$, corresponding to vibration mode $i$ :

$$
\ddot{q}_{i}+2 \beta_{i} \omega \dot{q}_{i}+\omega_{i}^{2} q=-\Gamma_{i} \ddot{X}_{0}(t) ;
$$

where $\beta_{i}$ is the relative damping value for vibration mode $i$,

$-\Gamma_{i}=\phi^{T} M E_{x}$ is the modal contribution factor.

Therefore, if we are dealing with a linear system, the solutions of the motion equations for systems with $n$ degrees of freedom shall serve as a basis for resolving the linear oscillator problem.

4. Integrate the systems of equations.

In order to solve equation (9), we used Duhamel's integral:

$$
q_{i}(t)=\frac{\Gamma_{i}}{\omega_{i}} \int_{0}^{t} \ddot{X}_{0}(\tau) \mathrm{e}^{-\beta_{i} \omega_{i}(t-\tau)} \cdot \sin \omega_{i}^{D}(\mathrm{t}-\tau) \mathrm{d} \tau
$$

where $\omega_{i}^{D}=\omega_{i} \sqrt{1-\beta_{i}^{2}}-$ is the eigenfrequency (damping included).

Determining the support reaction in the structure's design model requires solutions for all $n$ equations. We tracked the displacement of node points by superposing system reactions to all vibration modes.

5 . Find the displacement in specific nodes.

The amplitude of vibration mode $\mathrm{j}$ can be found through the following equation:

$$
u_{i}(t)=\phi_{i} \cdot q_{i}(t) \text {. }
$$

6. Determine the force in the elements of the reference system.

Bearing in mind the construction mechanics principle, which dictates that all forces are independent, we define "force" as a sum of forces that are caused by inertia and external impact:

$$
S_{k}(t)=S_{k F} \cdot F(t)+S_{k 1} \cdot J_{1}(t) ;
$$

where $S_{k F}$ is the force in the k section, caused by force $F=1, S_{k l}$ is the force in the $k$ section, caused by inertia $J_{j}=1$.

Equation (12) written in displacements shall look as follows:

$$
S_{k}(t)=S_{k F} \cdot F(t)+b_{k 1} \cdot u(t)
$$

where $b_{k 1}$ is the force matrix in the $k$ section, caused by unit displacement.

If the goal is to make our calculations more precise, accounting for dissipation, then equation (13) will look as follows:

$$
S_{k}(t)=S_{k F} \cdot F(t)+\left[b_{k 1}+\frac{S_{k 1} \cdot{ }_{1} \cdot \dot{u}(t)}{u(t)}\right] \cdot u(t) ;
$$

In equation (14), damping is described through an increase of stiffness.

\section{Results}

The process of determining forces is based on variables, which makes it even more challenging. However, for assessing the seismic stability of buildings, itisenoughtofindthemaximumforce: $S_{k} \max$.

The solution is simplified (without losing accuracy) if the system of differential equations is subjected to eigenmode expansion:

- integrating differential equations that describe mode $j$ of motion equations is simpler than integrating the original systems of equations;

- it is possible to achieve the desired accuracy level by finding not all $n$ eigenmodes, but only the modes from this interval: $S<n$.

\section{Discussion}

The method described in this paper is applicable not only to linear systems but also to systems where the dissipation matrices meet condition (8).

Assuming that vibration damping is proportionate to mass and stiffness, Rayleigh devised an equation where the C matrix from equation (8) looks as follows:

$$
C=\bar{a} \cdot M+\bar{b} K,
$$

where $\bar{a}$ и $\bar{b}$ are the proportionality coefficients for vibrations with different frequencies, dependent on the damping coefficient $\beta_{i}$.

As equation (5) allows for the eigenfunction expansion method, this means that each member of equation (5) will be expressed as a diagonal matrix.

The assumption that damping is proportionate is valid in some cases. But most structures with a broad range of construction material properties may require a disproportionate damping model. When we analyze structures together with their foundation, the foundation accounts for most of the damping. Therefore, we propose using damping matrices with different coefficients $\bar{a}$ и $\bar{b}$ for different structure parts. In this case, the damping matrix is not compliant with equation (8).

\section{Conclusions}

We have proposed a mathematical equation that describes the nature of shear link response to seismic and extreme loads.

Our method makes it possible to obtain an analytical solution for structures with proportionate and disproportionate damping by using the direct integration algorithm. 


\section{References}

Bataev, D. K.-S., Gaziev, M. A., Pinsker, V. A. and Chepurnenko, A. S. (2016). Calculation theory for shrinkage stresses in cellular concrete wall panels in carbonation processes with account of creep. VESTNIK MGSU (Monthly Journal on Construction and Architecture), 12, pp. 11-22.

Chepurnenko, A. S., Saibel, A. V., Yazyev, B. M. and Danilova-Volkovskaya, G. M. (2016). Determination of ultimate loads for concrete slabs based on concrete deformation theory of plasticity. Modern Science and Innovation, 1, pp. 93-98.

Chepurnenko, A. S., Savchenko, A. A. and Chepurnenko, V. S. (2019). Applied element method in the solution of plane problems in the theory of creep. Materials Physics and Mechanics, 42 (4), pp. 455-460. DOI: 10.18720/MPM.4242019_10.

Golykh, O. V., Nguyen, C. T. and Dang, K. A. (2010). Elastic-plastic inserts in buildings of complex macrostructure, their rigidity characteristics and effect on intense-deformed condition of buildings at nonuniform deposits. Bulletin of Civil Engineers, 1, pp. 51-55.

Golykh, O. V., Pletnev, V. I. and Rutman, Yu. L. (2011). Buildings with a complex macro structure and non-linear shear links under extreme impact. Saint Petersburg: Lap Lambert Academic Publishing, 101 p.

Nguyen, H. H. and Kondratieva, L. N. (2013). A study of elastic-plastic inserts' impact on the free vibration of a polyhedral shell. In: Proceedings of the $25^{\text {th }}$ International Conference "Mathematical and Computer Simulation in Mechanics of Solids and Structures. Methods of Boundary and Finite Elements". Saint Petersburg: Saint Petersburg State University of Architecture and Civil Engineering, pp. 145-146.

Nidzhad, A. Ya. (2014). Realization of macromodel method for frame structures design under maximum design earthquake. Modern Problems of Science and Education, 2. [online] Available at: https://science-education.ru/ru/article/ view?id=12449 [Date accessed 30.08.2020].

Omori, F. (1900). Seismic experiments on the fracturing and overturning of columns. Publications of the Earthquake Investigation Committee in foreign languages, 4, pp. 69-141.

Pletnhov, V. I. and Nguyen, C. T. (2011). Experimental research of deformation seams of various width in the bridges of buildings of complicated macrostructure. Bulletin of Civil Engineers, 1, pp. 55-57.

Rutman, Yu. L. (2012). The complex plasto-elastic deformation model of mechanical multiple freedom degree system. Bulletin of Civil Engineers, 1, pp. 117-120.

Rutman, Yu. L. (2013). Accounting the hardening in the elastic-plastic macromodel. Bulletin of Civil Engineers, 4, pp. 110-114.

Rutman, Yu. L., Kovaleva, N. V. and Skvortsov, V. R. (2007). Determining the parameters of a force diagram for structural elements subject to plastic deformation. In: Proceedings of the $22^{\text {nd }}$ International Conference "Mathematical and Computer Simulation in Mechanics of Solids and Structures. Methods of Boundary and Finite Elements". Saint Petersburg: Research Center MORINTECH, pp. 220-225.

Samsonov, A. V. (2003). Rational structural design and spring-loaded insulation of buildings under the dynamic impact. PhD Thesis in Engineering. Saint Petersburg: Saint Petersburg State University of Architecture and Civil Engineering.

Sanchez-Ricart, L. and Plumier, A. (2008). Parametric study of ductile moment-resisting steel frames: A first step towards Eurocode 8 calibration. Earthquake Engineering and Structural Dynamics, 37 (7), pp. 1135-1155. DOI: 10.1002/eqe.809.

Simbort, E. (2011). Comparison of nonlinear dynamic analyses performed by both single and multi degree of freedom systems. Magazine of Civil Engineering, 6, pp. 23-27.

Smirnov, A. A. (2008). Specifics of assessing the wind and seismic resistance of buildings with a complex macrostructure and their rational design. PhD Thesis in Engineering. Saint Petersburg: Saint Petersburg State University of Architecture and Civil Engineering. 


\title{
АНАЛИЗ МЕТОДИКИ АНАЛИТИЧЕСКОГО РАСЧЕТА СДВИГОВЫХ СВЯЗЕЙ НА СЕЙСМИЧЕСКИЕ И ЭКСТРЕМАЛЬНЫЕ НАГРУЗКИ
}

\author{
Лидия Никитовна Кондратьева*, Александр Васильевич Кузнецов, Екатерина Александровна \\ Моисеева \\ Санкт-Петербургский государственный архитектурно-строительный университет \\ 2-ая Красноармейская ул., 4, Санкт-Петербург, Россия \\ *E-mail: kondratjevaln@yandex.ru
}

\begin{abstract}
Аннотация
Статья посвящена анализу аналитического метода расчета на сейсмические и экстремальные воздействия зданий сложной макроструктуры с упругопластическими вставками, которые работают на сдвиг. Методы: В статье приведен анализ работ, посвященных выборам моделей сложного упругопластического деформирования механической системы с несколькими степенями свободы; прочности и устойчивости зданий сложной макроструктуры с нелинейными сдвиговыми связями при динамических и экстремальных воздействиях; методикам расчета зданий с упругопластическими вставками с учетом пластических шарниров стальных каркасов. Результаты: Аналитический метод применен для линейных и нелинейных систем с $n$ степенями свободы. Предложено математическое выражение, описывающее характер работы сдвиговых связей на сейсмические и экстремальные нагрузки. Методика позволяет получить аналитическое решение с использованием алгоритма прямого интегрирования для строительных конструкций с пропорциональным и непропорциональным демпфированием. Обсуждение: Для большинства сооружений с широким диапазоном свойств строительных материалов необходимо применение модели непропорционального демпфирования. Получено решение уравнений с использованием алгоритма прямого интегрирования с непропорциональным демпфированием. При больших значениях динамических нагрузок арматура сдвиговых вставок работает в пластической стадии.
\end{abstract}

\section{Ключевые слова}

Аналитический метод расчета, сейсмическая нагрузка, экстремальное воздействие, упругопластическая вставка. 